\title{
REINTERPRETACIONES, RESISTENCIAS Y NEGOCIACIONES EN LA PRISIÓN POLÍTICA ARGENTINA 1974-1983'
}

\author{
REINTERPRETATIONS, RESISTANCE AND NEGOTIATIONS IN \\ ARGENTINIAN POLITICAL PRISON 1974-1983
}

\author{
Débora D’Antonio \\ Doctora en Historia por la Universidad de Buenos Aires \\ e investigadora del CONICET \\ Ciudad de Buenos Aires, Argentina \\ deboradantonio@hotmail.com
}

Resumen: La creciente penetración del Estado autoritario sobre la sociedad civil durante los años sesenta y setenta tuvo como corolario una transformación profunda de los aparatos de captura. Las cárceles comenzaron a colmarse de presos y presas políticos y adquirieron una fuerte unidad en los tratamientos penitenciarios para quebrar a esta población ideológica y subjetivamente. En el penal de Villa Devoto fueron centralizadas las presas políticas a partir del último tercio del año 1975. La ubicación preferencial de esta cárcel, en un barrio de la capital del país, hizo que se convirtiera en un sitio muy expuesto, como una suerte de vidriera, a la mirada fiscalizadora de los organismos internacionales de derechos humanos, de los vecinos del barrio y en general, de la opinión pública. Esta particularidad les dio una ventaja a las presas políticas que supieron aprovechar en su favor para reclamar algunos derechos. En este artículo, a partir de las memorias, cartas personales y entrevistas realizadas a las ex presas políticas, busco comprender las formas en las que estas mujeres desplegaron sus resistencias, las negociaciones que encararon para mejores sus condiciones de vida y la construcción de alianzas que articularon con familiares e instituciones con el fin de denunciar los vejámenes y las violaciones a los derechos humanos que se cometían en las cárceles.

\begin{abstract}
The increasing penetration of the authoritarian state over civil society during the sixties and seventies had as corollary a profound transformation of capture devices. The prisons began with political prisoners and gained a strong unit in correctional treatments to break the population ideological and subjectively. In the Villa Devoto prison were centralized political prisoners from the last third of 1975 . The prime location of this prison, in a suburb of the capital, became a very exposed site, like a kind of glazed, for the regulatory gaze of the international human rights, the neighbors and general public opinion. This fact has enabled the political prisoners fight for some rights. This article, based on the memoirs, personal letters and interviews with former political prisoners, aims at understand the ways in which these women displayed their resistance, negotiations faced for better living conditions and building partnerships they articulated with family and institutions in order to report the harassment and human rights violations suffered in prisons.
\end{abstract}

\footnotetext{
${ }^{1}$ Artigo submetido à avaliação em 01/08/2013 e aprovado para publicação em 15/10 /2013
} 
Outros Tempos, vol. 10, n.16, 2013 p. 171-193. ISSN:1808-8031

\section{INTRODUCCIÓN}

Desde fines de la década del sesenta en Argentina, tanto la centralización en cárceles de máxima seguridad, ensayada conjuntamente por administraciones civiles y militares, como el flujo de presos y presas políticos, tuvieron una fuerte progresión y aumento respectivamente. Esta tendencia se consolidó a partir de la tensa coyuntura política del año 1974 con la declaración del Estado de sitio por parte del Poder Ejecutivo, y más aún, luego del golpe del 24 de marzo de 1976. Numerosos fueron los cambios operados en las prisiones en esta etapa y la mayoría de las veces brutalmente represivos. El propósito del poder penitenciario fue afectar de manera directa la cotidianeidad de quienes allí habitaban, y por esa vía, desarticular toda resistencia. Sin embargo, a pesar de los múltiples esfuerzos realizados para apuntalar esta política, ostensible en decretos, normativas y reglamentos públicos y secretos, la misma no alcanzó debidamente los objetivos planteados. En la mayoría de los casos, los varones y las mujeres encarcelados sobre quienes se impusieron estas tecnologías represivas, lograron revertir el aplastamiento subjetivo que implicaban estos tratamientos, y convertir a la prisión, en un espacio de transferencia y de circulación política.

En este artículo, a partir de las memorias, cartas personales y entrevistas realizadas a las ex presas políticas encerradas por esos años en la cárcel de Villa Devoto de la ciudad de Buenos Aires, me propongo analizar las prácticas que, a modo de respuesta a estas estrategias desplegadas por el poder penitenciario, ensayaron estas mujeres en tanto reinterpretaron, resistieron, negociaron y se apropiaron de diversos sentidos normalizadores que circulaban en sistema penitenciario en este período histórico.

Esta dinámica resulta clave para desentrañar el rol que cumplió la cárcel legal durante la última dictadura militar ${ }^{2}$, ya que a la par que conformó el aspecto visible de la represión estatal y funcionó como una cortina de ocultamiento de los espacios de encierro clandestinos, se tornó plataforma de denuncia de los presos y presas políticos de las violaciones a los derechos humanos.

\section{La institucionalización del encierro}

\footnotetext{
${ }^{2}$ Denomino cárcel legal a las unidades penitenciarias que tuvieron cautivos a los presos y presas políticos por prerrogativa del Poder Ejecutivo, por condenas de la justicia civil o por condenas de la justicia militar. Estos espacios se diferencian de los centros clandestinos de detención de carácter oculto e ilegal que se erigieron en distintas dependencias de las Fuerzas Armadas o de las Fuerzas de Seguridad y que tuvieron por finalidad secuestrar, torturar y asesinar convirtiendo a sus detenidos y detenidas en desaparecidos.
} 
Outros Tempos, vol. 10, n.16, 2013 p. 171-193. ISSN:1808-8031

Entre las presas reunidas en Villa Devoto había importantes diferencias porque mientras unas eran obreras otras eran estudiantes provenientes de las clases medias. También había quienes eran oriundas de zonas rurales y otras nacidas en las grandes ciudades del país. Además había militantes de organizaciones políticomilitares y otras de grupos de la izquierda tradicional. También estaban las que venían, de organizaciones sociales o las que tenían militancia sindical. Asimismo aunque la mayoría eran mujeres jóvenes había grupos de mujeres de mediana edad. A pesar de estas diferencias sociales, políticas y culturales, a todas estas mujeres, las unificaba un aire de familia propio de una época histórica de fuerte ascenso de la movilización y de la organización política. ${ }^{3}$ De este modo activistas gremiales, cuadros de partido, jefas guerrilleras, simpatizantes, "independientes”, familiares, abogadas, jóvenes y ancianas estuvieron juntas en las cárceles por un año, por dos o por seis, y en algunos casos hasta por diez. Para algunas mujeres, la cárcel de esta etapa fue su primera experiencia. Otras sin embargo, habían estado encarceladas en períodos anteriores, fundamentalmente durante las dictaduras de los presidentes de facto: Juan Carlos Onganía (1966-1970) y Alejandro A. Lanusse (1971-1973). Esto les permitía tener un conocimiento más afinado acerca del significado de ser un preso o una presa política bajo una dictadura militar. A pesar de esto, Alicia, una activista rosarina organizada en el Partido Revolucionario de los Trabajadores y en el Ejército Revolucionario del Pueblo (PRT-ERP), una agrupación armada de extracción marxista, sostuvo que la experiencia carcelaria por la que muchas activistas habían pasado previamente, en los años sesenta, no alcanzaba para comprender la lógica represiva que se articuló durante la última dictadura militar (1976-1983). Cuenta Alicia: "Hubo compañeras que habían estado presas antes, y transmitieron su experiencia. Pero como siempre hay mucho nuevo, sobre todo la intensidad y el alcance de la represión, hubo que aprender de uno mismo y de la solidaridad". ${ }^{4}$

Si bien la prisión política fue un espacio mucho más previsible que los centros clandestinos de detención, tuvo en relación con experiencias anteriores de encierro, numerosas singularidades. Por eso, no todo lo que se conocía o se había experimentado años atrás pudo ser puesto en práctica en esta nueva etapa. Nora, una ex

\footnotetext{
${ }^{3}$ Claudia Gilman escribió que el rasgo que cohesiona a esta época y que la provee de "una entidad temporal y conceptual" y de "un espesor histórico propio" es puntualmente la experiencia de la revolución cubana. Esta experiencia habilita nuevos sentidos en la práctica de movilización y organización de numerosos sectores en América Latina. GILMAN, Claudia. Entre la pluma y el fusil. Debates y dilemas del escritor revolucionario en América Latina. Buenos Aires: Siglo XXI, 2003, p. 36.

${ }^{4}$ Entrevista de la autora a Alicia, agosto de 2008, Buenos Aires.
} 
Outros Tempos, vol. 10, n.16, 2013 p. 171-193. ISSN:1808-8031

presa política describe en un carta destinada a un familiar lo que sucedía en Olmos, una antigua penitenciaria de las afueras de la ciudad de La Plata, un año antes del golpe de Estado. Según su relato, la cárcel de Olmos, aunque muy represiva al comienzo del año 1975, fue mucho más indulgente que la comisaría donde Nora había estado detenida antes que la blanquearan ${ }^{5}$ y en la que había sido sometido a numerosos vejámenes y torturas. La rutina que Nora destaca respecto de cuánto duraba el recreo, las posibilidades que ofrecía la cocina del penal en términos de alimentación o las reglas de juego para las visitas, pone de manifiesto cierta previsibilidad en lo que podía llegar a suceder en esta cárcel respecto del tratamiento penitenciario, sobre todo comparadamente con la comisaría que era un espacio de detención clandestina. De alguna manera, la llegada a la cárcel, a cualquier de ellas, aunque esta fuera rigurosísima en su tratamiento, normalizaba la arbitrariedad del encierro: "Te cuento que al estar acá ya tenemos un par más de garantías para nuestra integridad física”. 6

Las experiencias de encierro anteriores a la llegada a la cárcel de Villa Devoto fueron diferentes para cada una de las mujeres, dependiendo justamente de cuan ilegal o clandestino era el espacio en el que habían sido recluidas. En este sentido si las comisarías exhibían numerosos mecanismos ilegales de detención, las cárceles dependientes de los servicios penitenciarios bonaerenses -como la de Olmos, por ejemplo-, de alguna manera los moderaba. Pero al mismo tiempo, la cárcel de Villa Devoto, enclavada en un barrio metropolitano de la capital del país, atravesada por múltiples arbitrariedades, ofrecía mayores garantías que las que se proporcionaban en una cárcel provincial. De alguna manera, la mayor institucionalización del encierro, aunque este fuera tremendamente violento, provocaba sobre todo en las presas políticas menos incertidumbre, ansiedad y angustia.

Es por ello que con todas las limitaciones, que fueron muchas, la cárcel de Villa Devoto donde estuvieron reunidas entre 1976 y 1978 mil doscientas presas políticas, otorgaba en términos generales, la posibilidad de dormir en una cama, tomar y comer algo caliente, aunque fuera mínimo, comunicarse de alguna forma con los familiares y, por sobre todas las cosas, socializar con otras compañeras. ${ }^{7}$

\footnotetext{
${ }^{5}$ El término blanquear alude a la legalización de los prisioneros y prisioneras políticos sea hecho esto por medio de un decreto del Poder Ejecutivo Nacional o por medio de una orden de un juez civil o militar.

${ }^{6}$ Carta de Nora escrita el 27 de marzo de 1975 y dirigida a su hermana desde la cárcel de Olmos. Ver el CD ROM editado en BEGUÁN, Viviana et al. Nosotras, presas políticas (1974-1983). Buenos Aires: Nuestra América, 2006.

${ }^{7}$ Aunque parezca contradictorio, las presas entrevistadas se refirieron a Villa Devoto como el "final" de una infeliz experiencia, aun cuando en sus relatos incluyeron la existencia durante el año 1974-5 de
} 
Outros Tempos, vol. 10, n.16, 2013 p. 171-193. ISSN:1808-8031

\section{Imágenes de la resistencia}

Las diversas formas que adquirió la oposición femenina a la vida carcelaria variaron según la coyuntura política local. Un momento importante fue el reingreso a las cárceles para los presos y presas políticos en el verano de 1974, luego de la liberación masiva que llevara adelante el gobierno del peronista de Héctor J. Cámpora en mayo del año anterior. Otro muy disímil fue lo sucedido a partir del Estado de sitio decretado por la presidenta María Estela Martínez de Perón en noviembre de 1974, todavía bajo un gobierno constitucional. También fueron muy diferentes los climas vividos en la cárcel tras el golpe de Estado de 1976, en el mundial de fútbol de 1978, la vista de la Comisión Interamericana por los Derechos Humanos en 1979 o la guerra de Malvinas de 1982. Cada una de estas situaciones dio lugar a nuevas formas y articulación de resistencias. Durante los años sesenta y primeros años setenta, la huelga de hambre fue uno de los métodos principales de lucha que llevaban adelante los presos y presas políticos. Todavía durante el año 1975, en pleno Estado de sitio, se podían desarrollar huelgas y actos públicos en los penales. Sin embargo esta forma de oponerse al tratamiento carcelario no pudo seguir sosteniéndose durante el último gobierno militar.

Graciela escribe que:

\footnotetext{
“...estamos haciendo huelga de hambre muy sentaditas todo el día en la cama... En pocas palabras les diré que una huelga de hambre es resistirse a comer la comida del penal, como protesta por no tener determinadas cosas. Así estuvimos 20 días en que solo tomamos mate, té y algunas galletitas que teníamos. Al cabo de unos días, cuando las autoridades empezaban a preocuparse porque se nos desmejoraba la salud, nos concedieron algunas de las reformas que pedíamos: dos días de visita, entrada de libros de estudio, mejor atención médica, etc." 8
}

En los relatos de las mujeres ex presas políticas, frente a estas restricciones que se fueron sucediendo en la experiencia carcelaria, fueron apareciendo con claridad

comandos clandestinos que ingresaban a este penal exhibiendo sus armas con el propósito de intimidarlas. Este es el caso del "Comando Nacionalista Juan Manuel de Rosas" cuyos volantes indicaban que se ejecutaría a las simpatizantes y adherentes del PRT-ERP. También es el caso del "Comando Valenzuela", una fuerza de choque construida ilegalmente por el Servicio Penitenciario Federal (SPF) con el fin de disciplinar a todas las mujeres recién llegadas a la cárcel. Ver BEGUÁN, Viviana et al. Nosotras, presas políticas, Op. Cit., p. 85.

${ }^{8}$ Carta de Graciela escrita en junio de 1975 y dirigida a un familiar desde la cárcel de Olmos. Entre los años 1974 y 1975 hubo dos huelgas de hambre con consignas tales como "Libertad a los presos políticos" y "Mejoras en las condiciones de vida". La primera que comenzó en el mes de mayo, duró 25 días y fue masiva entre los varones. En la segunda que se desarrolló a partir de junio de 1975, se sumaron un centenar de presas políticas, muchas de las cuales tenían consigo en sus celdas a sus niños pequeños. Ver el CD ROM editado en Begúan y et al, Op. Cit. 
las nuevas formas ideadas para sortear las múltiples trabas que se sucedían en el encierro:

\begin{abstract}
“...a las 11 de la noche abrían para ir al baño y para ir a buscar el colchón y la frazada, ¡bah! colchón, tenía unas manchas que era un asco... y nada más (...) no podías escribir, no tenías nada, entonces tenías que inventar y escribir en el cerebro. Yo decía escribo (...) porque la cosa era acordártelo todo de memoria para después escribirlo cuando bajabas, bueno, eso te llevaba horas, imagináte qué trabajo. Bueno eh... con los panes, también (...) porque qué ibas a hacer, no tenías nada blando para sentarte, además en invierno hacía frío, no tenías frazadas, no tenías nada, entonces los panes, yo no me los comía, tenía que hacer una evaluación, qué convenía, si comerse o no comerse el pan, muchas veces se usaba como soporte sobre la chapa, entonces para acostarme porque me daba más frío acostarme sobre la chapa, entonces ponía un pan, debajo de la cadera, un pan debajo de la cadera y un pan debajo de la rodilla, entonces me ponía de costadito y trataba de descansar, así de esa manera, a veces los panes también podían servir, si no hacías así, para modelar, entonces dedicabas un tiempo a modelar, claro que con el gran riesgo, que si te encontraban que habías modelado...". 9
\end{abstract}

De este modo un trozo de pan era utilizado ingeniosamente para ejercitar los músculos de la mano o el brazo, para descansar sobre él o simplemente para ser manipulado como un poco de alimento. Los materiales que ofrecía el penal, por escasos que fuesen, eran reciclados, y les permitían a las mujeres en las celdas o en los calabozos, afrontar las estrategias de humillación del cuerpo que los carceleros practicaban cotidianamente. $^{10}$

De toda esta primera etapa, donde las condiciones de encierro eran muy severas, las mujeres supieron sacar provecho de su reclusión en una cárcel metropolitana, moderna y con servicios como lo era la de Villa Devoto. Opina Haydee que en la medida en que se fue consolidando la condición de estar en una cárcel "vidriera", 11 las presas utilizaron esta particularidad para visibilizar las vejaciones a

\footnotetext{
${ }^{9}$ Entrevista de la autora a Irma, noviembre de 2008, Buenos Aires.

${ }^{10} \mathrm{El}$ tema de las múltiples formas que pueden asumir las "resistencias" ha sido originalmente analizado por el antropólogo y politólogo norteamericano James Scott. Este autor propone detenerse en las formas de resistencia soterradas de los grupos subordinados, especialmente en lo que él llama discurso "oculto". Este discurso remite a las manifestaciones lingüísticas, gestuales y prácticas de los grupos que desarrollan prácticas de forma clandestina sin que ellas deban derivar necesariamente hacia un enfrentamiento abierto con los poderes hegemónicos. Cfr. SCOTT, James. Los Dominados y el Arte de la Resistencia. México: ERA, 2000.

${ }_{11}$ "Cárcel vidriera" es un concepto nativo utilizado por las propias presas políticas para definir el complejo lugar que ellas tuvieron en Villa Devoto. Esta cárcel enclavada en un barrio de clase media porteña fue utilizada por el régimen militar para exhibir a estas mujeres como rehenes y trofeos de guerra mientras desaparecían a cientos de miles de activistas en los centros clandestinos de detención. En cierto modo la "cárcel vidriera" funcionó como la cara visible de una estrategia represiva doble que incluía una fase de carácter ilegal.
} 
Outros Tempos, vol. 10, n.16, 2013 p. 171-193. ISSN:1808-8031

las que eran sometidas en este penal y para transferir el conocimiento que tenían de las violaciones a los derechos humanos que el régimen cometía en los centros clandestinos, por los que muchas de ellas habían pasado. La conciencia de esta condición les potenció su capacidad de gravitar en el penal con mayores ejercicios de insubordinación. Dice Haydee que "frente a la política de destrucción de la personalidad, a la que estábamos sometidas como política de Estado (...) eso nos permitió ejercer con una visión política ese lugar privilegiado, y realizar las denuncias en forma inmediata...", mucho más que sus compañeros varones ${ }^{12}$.

La resistencia femenina por las ventajas que acarreó su visibilidad pudo explotar ciertas prerrogativas que el dispositivo represivo no ofreció en otras áreas. Tal vez por este motivo las mujeres desarrollaron a lo largo de los años de encierro, un enfrentamiento bastante abierto con los poderes, sobre todo, en comparación con las posibilidades que ofrecían los penales del interior del país, federales o provinciales, donde estaban concentrados los presos políticos varones. Esta forma de resistencia la interpretamos como una ventaja de género que jugó a favor de las presas políticas.

Además las mujeres pudieron reclasificar su condición de ser rehenes del régimen penitenciario y militar. Denunciaron públicamente la reducción de sus derechos realizando cotidianamente un ritual performativo. Siguiendo a Diana Taylor en este punto, la noción de performance designa el proceso en el cual se lleva a cabo una acción experimentada como un espectáculo y supone un repertorio de conductas repetidas. ${ }^{13} \mathrm{Si}$ la performance que le otorga verosimilitud al Estado represor es la violencia repetida que se impone sobre los cuerpos, excluyendo de la comunidad política a los "inadaptados", la misma naturaleza dramatizada es la que les permite a las mujeres ir más allá de las condiciones de posibilidad impuestas por las interdicciones del régimen militar. Esta repetición es la que lleva a las presas políticas a no suspender sus reclamos por la ampliación de derechos en la vida penitenciaria, a no ceder en el enfrentamiento con carceleras y carceleros, y a no renunciar a entablar

\footnotetext{
${ }^{12}$ Comunicación personal de la autora con Haydee, intercambio por vía electrónica, julio de 2008.

${ }^{13}$ Diane Taylor analiza utiliza la noción de performatividad para analizar el caso de las Madres de Plaza de Mayo y señala que estas mujeres utilizan la clásica iconografía de la "madre", en tanto representación socialmente aceptada, para hundir su protesta en el corazón de la escena política argentina que es la Plaza de Mayo. Las madres hacen reaparecer con su performance reiterada, a sus seres queridos desaparecidos. Las pancartas, las fotos, los carteles, las siluetas, los nombres y las fechas lo escenifican. El cuerpo de estas mujeres, pero también el de sus hijos e hijas, a través de estas imágenes, se transforma en el escenario de la protesta y en el arma de combate. A través de la performance hacen visible lo que la dictadura quiso hacer invisible, que son sus hijos e hijas desaparecidos. Ver TAYLOR, Diane. Dissapearing acts. Spectacles of Gender and Nationalism in Argentina's "Dirty War". Durham and London; Duke University Press, pp. 183-222.
} 
Outros Tempos, vol. 10, n.16, 2013 p. 171-193. ISSN:1808-8031

un diálogo con el director del penal, por ejemplo, con el fin de obtener alguna ventaja o mejoramiento en algún rubro.

En efecto, muchas de las peticiones que realizaron las presas políticas fueron en momentos muy restrictivos del régimen penitenciario. La manera que tuvieron de reclamar frente a las autoridades del penal implicó la articulación de una resistencia colectiva y la obstaculización sistemática de cualquier medida caracterizada como perniciosa. Esta forma de solicitar o de reclamar agrupadamente era especialmente castigada en los reglamentos penitenciarios pues solo se podía requerir alguna cuestión puntual y en forma individual. Frente a esto, las mujeres dispusieron de la existencia de una delegada que se hiciese responsable de formular los reclamos para todas las mujeres del pabellón. Explica una ex presa política que por ese entonces encabezó los reclamos frente al poder carcelario: "De esta manera expresábamos el carácter político de nuestra permanencia en la cárcel". ${ }^{14}$

Observa Diane Taylor que teatralizar no remite necesariamente a la formulación de conductas artificiales, por el contrario, es el modo de manifestar y de poder captar la atención del poder o de la sociedad misma si esto fuera posible. Con este propósito de repetición se diseñaron "notas de reclamo, de denuncia, rechazo de comidas, gritos, campañas de hábeas corpus y recursos de amparo, gestiones masivas de visas, rechazo a acceder a ciertas imposiciones como requisas vejatorias y caminar con la cabeza baja y las manos atrás, etc.” 15

El grado de resistencia entonces que ejercieron las mujeres tuvo que ver con las condiciones de posibilidad de la cárcel "vidriera" en la que se encontraban. Un varón ex preso político militante del PRT-ERP, que como él mismo se definió, lo "pasearon" por todos los penales de máxima seguridad del país, se refirió a este tema de la oposición femenina argumentado que "ese grado de confrontación sólo fue factible en el marco de las condiciones de una cárcel con las características de Villa Devoto; nada de esto hubiera sido posible en un penal como el de Rawson, tan lejano, donde las condiciones de vida eran tremendamente malas". ${ }^{16}$ Mirta quien ha testimoniado en diversas oportunidades frente al Poder Judicial o en sede de organismos de derechos humanos, cuenta que en Devoto "los penitenciarios tenían una

\footnotetext{
${ }^{14}$ Ver BEGUÁN, Viviana et al. Nosotras, presas políticas, Op. Cit., p. 117.

${ }^{15}$ Ver ANTOGNAZZI, Irma. "La vida en las cárceles de mujeres durante la dictadura argentina", en ANTOGNAZZI, Irma y FERRER, Rosa. Del Rosariazo a la democracia del 83. Rosario: Universidad Nacional de Rosario, 1988, p.19.

${ }^{16}$ Entrevista de la autora a Julio, septiembre de 2008, Buenos Aires.
} 
Outros Tempos, vol. 10, n.16, 2013 p. 171-193. ISSN:1808-8031

actitud muy despectiva con nosotras (...) éramos como todas las mujeres, hincha pelotas”. La reflexión de Mirta permite dimensionar a la vez la activa insistencia de las mujeres con sus propias demandas y la violencia de género y sexual ejercida por los carceleros. Ante la violencia oral entonces llevada adelante por distintos agentes del poder penitenciario "las mujeres muchas veces nos manteníamos en silencio (...) pero sentábamos precedente de otra manera, por ejemplo: cuando nos llevaban compañeras a traslados [en los] que corrían peligro sus vidas, organizábamos jarreos". ${ }^{17}$ Esta era una manera expeditiva que les permitía dar un estado de alerta a todas las compañeras al mismo tiempo y que era utilizada con frecuencia sobre todo en los dos primeros años del régimen represivo para llamar la atención de los vecinos del barrio si se sospechaba que alguna de ellas podía ser sacada del penal para ser asesinada. Alicia sostiene que:

\footnotetext{
"cada vez que nosotras en Devoto teníamos una medida de fuerza por alguna emergencia, los compañeros nos mandaban mensajes desde sus cárceles diciéndonos que nos cuidáramos, que nos iban a matar. Creo que como hombres que crecieron en una cultura machista, por más esfuerzos que hicieran para sacarse de encima ese tipo de características, no podían dejar de cuidarnos y de tener miedo por nosotras". 18
}

Si bien a los varones presos políticos les costaba asumir que sus compañeras, pudieran confrontar abiertamente con el poder penitenciario militar, también es cierto que ellos no contaban con la ventaja de estar en la "vidriera" de la represión y que su resistencia debía desarrollarse de manera necesariamente solapada.

La reiteración frente al poder es lo que les permitió a las mujeres no cejar en sus insistentes demandas, reclamos y denuncias que, por otro lado, fueron extraídos de la cárcel de Villa Devoto por medio de la ayuda desinteresada de los familiares. Esta performance reiterada no solo fue particularmente útil a los fines de hacer conocer a nivel internacional las vejaciones que se cometían en las cárceles sino que les brindó de modo efectivo a las presas políticas mejores condiciones de vida.

Las mujeres construyeron, además de los reclamos directos al poder, otros niveles de organización y participación más encubiertos. Las conversaciones casi en forma de susurros por las noches, los encuentros en los baños del pabellón, las citas furtivas en la enfermería o en el recreo, los cruces en la misa de la capilla del penal, los

\footnotetext{
${ }^{17}$ CLARA, Mirta. "La situación de la mujer en la cárcel, 1976-1983", en http://www.pparg.org/pparg/carceles/globalidad/analisis, 1998, s/p.

${ }^{18}$ Entrevista de la autora a Alicia, agosto de 2007, Buenos Aires.
} 
Outros Tempos, vol. 10, n.16, 2013 p. 171-193. ISSN:1808-8031

rumores que se interceptaban de las palabras de los familiares y las cartas con sus lenguajes velados, se convirtieron en espacios de intercambios de miradas y gestos, de papelitos escritos y de objetos fabricados con el ánimo de compartir alguna sociabilidad o información. Las presas políticas tendieron clandestinamente diversos puentes de comunicación lo que les facilitó el desarrollo de novedosas formas de conexión. Los pequeños escritos envueltos que circulaban a través del correo por letrinas (un hilo tejido de un largo que pudiera traspasar los diferentes pisos del penal con una envoltura en la punta simulando un anzuelo), el caramelo (un diminuto papel envuelto en la boca o en la oreja), el canuto en la vagina o en el ano (un papel de cigarrillo escrito sellado con fuego con datos o novedades), los mensajes en libros que transitaban las celdas y que debían ser interpretados, la comunicación a través de las ventanas o por medio de un código tipo Morse en los caños de los camastros, les permitió construir una red de información que se armaba y rearmaba todo el tiempo. ${ }^{19}$

En las entrevistas realizadas, las ex presas se han referido en numerosas oportunidades al humor como una forma concreta de disfrazar la disidencia y que les ayudaba, además, a enfrentar la angustia provocada luego de la destrucción de la requisa por los carceleros, la indefinida incomunicación con el exterior o el dolor por la pérdida de un ser querido. Explica Alicia que fue el humor "el mecanismo de defensa que nos permitió resistir y sobrevivir (...) y burlar las estrategias que los represores habían implementado cuidadosamente para destruir nuestra moral y nuestros cuerpos (...) gracias a esas risas fuimos interiormente libres contra todo". ${ }^{20}$ Cada acción de este tipo expresaba un nuevo nicho de autonomía donde se constituía de modo práctico un discurso político oculto y puesto al del poder penitenciario.

Sobre esta base, el presidio funcionó como una escuela clandestina de distribución de bienes culturales. Las mujeres hacían circular cursos de alfabetización para quienes lo necesitaran. Se brindaron de modo secreto, conocimientos de historia o de política, y en todas las instancias se retransmitían permanentemente los conocimientos con los que cada una de ella contaba. La organización se aplicaba a todas las actividades, lo que permitía definir de forma cuidadosa, planeada y rotativa quién limpiaba, quién cocinaba, quién conseguía medicamentos para las compañeras con alguna dolencia crónica, etcétera.

\footnotetext{
${ }^{19}$ Ver una descripción densa de este tema en GUGLIELMUCCI, Ana. "Vida cotidiana en la cárcel de Villa Devoto", en Lucha Armada en la Argentina, n. ${ }^{\circ}$ 7, Buenos Aires, 2006, pp.35-50.

${ }^{20}$ Entrevista de la autora a Alicia, agosto de 2007, Buenos Aires.
} 
Outros Tempos, vol. 10, n.16, 2013 p. 171-193. ISSN:1808-8031

Es importante señalar, como sostiene Mirta al comparar la experiencia que desarrollaron las mujeres en las cárceles respecto de los campos clandestinos de detención, que si esta fue diferente lo fue porque:

\begin{abstract}
“en la cárcel existía una organización interna inventada por nosotras. Una organización estructurada, un poco clandestina, un poco abierta, sobre la que el enemigo intentaba avanzar, ya que siempre trató de romper el modus vivendi del conjunto de nosotras. [. . . día a día, pujaban por tener juntas una cotidianeidad que les estaba prohibida por ese "estar fuera del tiempo y del espacio".. ${ }^{21}$
\end{abstract}

Es decir que a la condición de visibilidad que tenía Villa Devoto se le agregaba que con todas las limitaciones hubo posibilidad de organización política de las internas. Y fue esta organización metódica la que les facilitó coordinar productivamente el tiempo carcelario y alejarse del tiempo muerto que era la propuesta sustentada por los penitenciarios. Sabemos que esta organización se sostuvo en la actividad discutida y planificada de los presas por barrio, que en la jerga carcelaria aludía a un conjunto reducido de celdas, que a la vez construían lazos con otros barrios de otros pisos u otros pabellones. Cada pabellón estaba conducido por una presa “cuadro político", y, a la vez, en los pabellones había otro tipo de direcciones o coordinaciones que ayudaban a resolver otras problemáticas de la vida en el encierro. Se mantenía, entonces, una suerte de estructura celular de carácter clandestina que los carceleros y carceleras en principio debían desconocer, lo que permitía ocultar el rol de aquellas mujeres que cumplían roles dirigentes en el presidio. Estos lazos horizontales definían una de las dinámicas más importantes del penal que a la vez se superponía con las jerarquías políticas partidarias existentes.

Durante un tiempo se mantuvieron las estructuras políticas de las organizaciones, sobre todo de aquellas de carácter político-militar que acumularon mayor cantidad de mujeres presas como es el caso de Montoneros de extracción peronista y del PRT-ERP; y esa fue la base inicial de los ordenamientos internos. Sin embargo más adelante esta modalidad sería reinterpretada por las presas con el propósito de abrir nuevos juegos y posibilidades políticas para aquellas mujeres que habían tenido o aún tenían en sus organizaciones, responsabilidades intermedias.

\footnotetext{
21 Testimonio citado en ACTIS, Munú, et al. Ese Infierno. Conversaciones de cinco mujeres sobrevivientes de la ESMA. Buenos Aires. Editorial Sudamericana, 2001, p. 302.
} 
Outros Tempos, vol. 10, n.16, 2013 p. 171-193. ISSN:1808-8031

Estas prácticas modificaban permanentemente el espacio penitenciario, el cual estuvo trasvasado por infinidad de pequeñas demandas, contradicciones y transacciones cotidianas de las presas entre sí, de las organizaciones políticas y de ellas con los penitenciarios. Este espacio no fue un simple telón de fondo donde las presas "actuaron", sino que, por el contrario, fue el territorio donde las subjetividades, proyectos e intervenciones de cada una de ellas y de sus grupos de pertenencia, se expandió en orden a sus destrezas de supervivencia.

\section{Autonomía y contrapoder}

La autonomía de las mujeres se manifestó en la forma en que resignificaron la clasificación operada por el servicio penitenciario a mediados del año 1977. El que era por entonces director del Servicio Penitenciario Federal dependiente del Poder Ejecutivo Nacional, coronel Jorge Dotti ${ }^{22}$, extremó las condiciones de seguridad en Villa Devoto y anunció el "Plan Conducta y Libertad". Este consistía en presionar de distintas maneras a las presas políticas para doblegarlas por medio de reducciones de derechos y de sanciones sistemáticas cumplidas en calabozo. Entre muchos otros aspectos este plan apuntalaba a una ruptura total de las presas políticas con la realidad exterior, prohibiendo el ingreso de cualquier tipo de material escrito como diarios, revistas o libros e impidiéndoles la utilización de papel, lápices y lapiceras. También se les proscribió a las presas políticas todo tipo de actividad física o destreza manual con el propósito de desarraigarlas y mantenerlas en un estado de vegetación. Con estas disposiciones se anuló de forma reglamentaria la posibilidad de hacer algún tipo de préstamo sean estos elementos de limpieza, alimentos o alguna prenda de vestir. Se restringieron además, fuertemente las horas de recreo y de visitas de los familiares y se redujo notablemente la posibilidad de comprar artículos en la proveeduría del penal. Finalmente se impidió bajo amenaza de severos castigos, reírse o cantar.

El objetivo del plan era inducir a las presas políticas a la firma de un acta pública de arrepentimiento para dominarlas políticamente. Quien optase por la firma de esta acta podía ser considerada por el régimen penitenciario como una presa política

\footnotetext{
${ }^{22}$ Jorge Antonio Dotti alcanzó el grado de Coronel en el arma de Infantería y posteriormente formó parte de los grupos de Oficiales de Inteligencia Militar. En 1971 estuvo al frente de la dirección de Coordinación Federal de la Policía Federal. Desde enero de 1976 hasta 1980, ya como coronel retirado, dirigió el Servicio Penitenciario Federal. Se lo considera responsable de los delitos cometidos en las unidades carcelarias que de él dependían, así como también de lo sucedido en el Centro Clandestino de Detención "El Vesubio", dependiente del SPF. Murió en 1991. Ver decreto presidencial N. ${ }^{\circ} 262$ donde se designa al coronel (RE) Jorge Antonio Dotti. Ver Boletín Penitenciario del Servicio Penitenciario Federal, N. ${ }^{\circ} 1068$ del 28/01/76.
} 
Outros Tempos, vol. 10, n.16, 2013 p. 171-193. ISSN:1808-8031

"recuperable", dejando atrás su pasado de "irrecuperabilidad" asociado con los apresados de máxima peligrosidad. ${ }^{23}$

Para llevar a cabo el plan, las internas fueron observadas sistemáticamente por celadores, capellanes y un cúmulo de profesionales tales como: asistentes sociales, psicólogos, psiquiatras o sociólogos. Formaron parte de la evaluación las cartas que estas mujeres escribían a sus familiares y amigos -que analizaremos en el próximo apartado-, así como los antiguos partes de sanción. Luego de confeccionar una clasificación de la población de presas políticas se pasaba a la segunda fase de relocalización en diversos pabellones, según el grado de compromiso con las directivas penitenciarias. El instrumento clave para alcanzar una clasificación fidedigna fue el informe interdisciplinario donde se analizaban las diversas aristas de la conducta de estas mujeres. También en estos informes se plasmaron y se fundamentaron los rechazos o la aceptación a los pedidos de cambio de localización secundados por algún área del poder carcelario. Un ejemplo resulta del siguiente informe:

\begin{abstract}
"Su ingreso a esta unidad se ha caracterizado por una constante indisciplina e inadaptación a los reglamentos y normas que rigen la vida de la prisión. Conviven y comparten alojamiento con elementos de neta extracción subversiva, haciendo causa común en todo movimiento de fuerza o rebeldía que se implemente. Por lo expuesto $\mathrm{y}$ antecedentes obrantes, esta jefatura permite aseverar que no han surgido indicios que induzcan a sostener un determinado grado de recuperación en las usantes, considerándose en consecuencia inconveniente otorgar el beneficio solicitado". ${ }^{24}$
\end{abstract}

Tras este diagnóstico se llegaba a la clasificación en tres niveles o grupos, según el grado de adaptabilidad a estas normas y en paralelo, según el grado de ruptura con el pasado militante. ${ }^{25}$ El Grupo 1 ocupaba tres de los cinco pisos más altos de la planta de celulares de Villa Devoto. Este régimen, que era el más estricto y el de máxima seguridad, era el que contaba paradójicamente con más mujeres. Allí era donde casi todo estaba prohibido: recibir diarios, tener recreos al aire libre, realizar

\footnotetext{
${ }^{23}$ Ver BEGUÁN, Viviana et al. Nosotras, presas políticas, Op. Cit., p.216.

${ }^{24}$ Informe enviado al juez federal del Juzgado N. ${ }^{\circ}$ 3, Héctor Adamo en la ciudad de la Plata, 7 de junio de 1978, firmado por el Director General del Régimen Correccional. Citado en BEGUÁN, Viviana et al. Nosotras, presas políticas, Op. Cit., p.272.

${ }^{25}$ Una interpretación muy interesante es la que sostiene el antropólogo Santiago Garaño respecto de la particular apropiación que los presos y presas hicieron de estas clasificaciones y de las consecuencias que esta tuvo en la memoria sobre ese pasado. Según este autor, esta clasificación llevó a que los presos y presas articularan una comunidad de memoria fuertemente anclada al lugar que les fue asignado en el penal por aquellos años. Cfr. GARAÑO, Santiago. Entre resistentes e "irrecuperables": Memorias de ex presas y presos políticos (1974-1983). Tesis de Licenciatura, Facultad de Filosofía y Letras, UBA, 2008, 92-94.
} 
Outros Tempos, vol. 10, n.16, 2013 p. 171-193. ISSN:1808-8031

ejercicios físicos o llevar adelante la experiencia del economato. ${ }^{26}$ En el Grupo 2, los penitenciarios englobaban al núcleo de mujeres que estaban aún en observación. Estas presas eran ubicadas en otro piso y se les permitía algunas veces por semana, la entrada de diarios y revistas, así como algunas horas de recreo. En la planta baja, la más accesible a los servicios del penal, se reunían las mujeres del Grupo 3 que tenían, tal como el penal lo llamaba, un "régimen de beneficios". En este espacio se incluían las visitas, una mayor cantidad de horas de recreo, el ingreso de los diarios, la escucha de la radio, un régimen de celdas abiertas, y la posibilidad de hacer gimnasia y trabajo manual en las celdas.

Mientras los penitenciarios evaluaban y definían las formas de agrupamiento, las mujeres, como en una suerte de contrapoder, debatían la clasificación en las celdas y en los pabellones con el objetivo de reducir los márgenes de intervención en la subjetividad de las prisioneras. Tras discusiones pacientes entre ellas, en términos generales, le dieron cohesión a los diversos grupos rechazando la política del penal que suponía hacerles creer que las libertades dependían de la colaboración. Explica Alicia que: "lo cierto es que la libertades alcanzadas tuvieron poca relación con esta clasificación, dependiendo siempre mucho más de la situación política externa En sus intentos de separarnos tuvieron muy, pero muy escaso éxito". ${ }^{27}$

El fomento de la individualización y atomización y la clasificación diferenciada según grados de peligrosidad, generó entre las internas un redoblamiento del esfuerzo en favor de la resistencia, mediante la a veces casi inaprensible construcción de redes horizontales cohesivas y solidarias. Este aspecto liminal de la resistencia, a nuestro parecer, funcionó mucho más eficazmente que la clasificación penitenciaria misma. Relacionado con este punto, las mujeres en Villa Devoto fueron menos rigurosas que los varones a la hora de valorar lo que consideraban una defección política. Si bien existía entre ellas el conocimiento de la figura del "juicio revolucionario" para encuadrar, por ejemplo, los actos caracterizados como de "traición" o "delación", esta forma coercitiva de manejo de lo político se llevó adelante en muy escasas oportunidades entre las compañeras en el penal. ${ }^{28}$

\footnotetext{
${ }^{26}$ Las presas llamaban "economato" a la socialización del dinero que les enviaban sus familiares y que era utilizado comunitariamente para cubrir las necesidades de un determinado conjunto de mujeres por pabellón o celdas, dependiendo de cada coyuntura.

${ }^{27}$ Entrevista de la autora a Alicia, agosto de 2008, Buenos Aires.

${ }^{28}$ Entre nuestras entrevistadas ninguna recuerda el "juicio político" en el interior de la cárcel como algo especialmente utilizado para disciplinar a las presas "díscolas". Sí se acuerdan, sin embargo, de desaires y ciertas prácticas de aislamiento para con las mujeres calificadas con de una moral política dudosa, tal vez
} 
Outros Tempos, vol. 10, n.16, 2013 p. 171-193. ISSN:1808-8031

Todo acto penitenciario fue entonces reinterpretado. Por ejemplo, los traslados entre pabellones o celdas que eran consumados por los penitenciarios como una forma de desmembrar toda ligadura social, fueron utilizados ventajosamente para "hacer circular información al interior de los penales y en el caso de los varones, entre penales, desarrollando nuevos vínculos solidarios con otros presos". ${ }^{29}$ A esta cuestión se le sumó la posibilidad de recurrir a estos movimientos internos para conocer mejor las distintas secciones del penal y para recibir información de las compañeras que habían estado detenidas en los centros clandestinos y trazar un mapa global de la actividad represiva del Estado. Otro tema que fue reclasificado por las presas políticas por ejemplo, fueron las tareas de la "fajina". Se llama fajina a los quehaceres rotativos de limpieza en área comunes que en el universo carcelario son asignados a los recién llegados y que a modo de pagar "el derecho de piso", estos lo llevan adelante como parte de un esfuerzo extra por ser aceptados. La "fajina" que puede ser vista como una actividad degradante, terminó siendo entre las presas políticas un acto de cuidado y de solidaridad hacia las otras compañeras. Al mismo tiempo la "fajina" funcionó de forma positiva a la hora de apropiarse del espacio de encierro.

Si bien muchos de los actos de resistencia en el interior del penal fueron de supervivencia porque apuntaban a lograr cosas mínimas como el alimento, el abrigo o el fin de los encierros en los calabozos, hubo otro tipo de actividad de un carácter más abierto políticamente y que tuvo por finalidad captar la atención de los vecinos del barrio de Devoto y desde allí de la opinión pública. Estos actos de resistencia más expuestos fueron desde el golpeteo de jarros en las ventanas hasta el diseño de una logística para sacar en forma clandestina pequeños escritos en distintos formatos que narraban los maltratos de la vida en el encierro. También se destacan las interpelaciones que cada una de las presas políticas les hizo a los funcionarios de la Cruz Roja o de otros organismos fiscalizadores a nivel internacional que ingresaron al penal para corroborar los rumores de ultrajes y agravios. Cualquier visita externa fue aprovechada para realizar denuncias sobre apremios ilegales, como en el caso del ingreso a la cárcel de personal de Amnesty International en noviembre de 1976.

por haber aportado datos a los carceleros sobre el funcionamiento interno de las presas. La antropóloga Ana Guglielmucci, no obstante afirma que "la conducción de Montoneros, por ejemplo, llegó a realizar juicios revolucionarios dentro de la cárcel por medio de los cuales se des promovía a la compañera de su nivel de jerarquía y se prohibía al resto del grupo el trato con ella". Ver GUGLIELMUCCI, Ana. "Vida cotidiana en la cárcel de Villa Devoto", Op. Cit, p. 50.

${ }^{29}$ Entrevista de la autora a Alicia, abril de 2006, Buenos Aires. 
Outros Tempos, vol. 10, n.16, 2013 p. 171-193. ISSN:1808-8031

Es importante señalar que en la coyuntura del Mundial de Fútbol, las mujeres discutieron con sus familias las consecuencias políticas del mismo. Este fue un evento deportivo que se desarrolló a mediados de 1978 en la Argentina frente a la presencia de numerosos visitantes extranjeros, periodistas y reporteros gráficos, cuando todavía se practicaba una represión muy cruenta y de carácter clandestino hacia los opositores políticos. El Mundial sirvió tanto para enmascarar la política represiva que el régimen militar desarrollaba en distintas cárceles y en centros clandestinos de detención como para contrarrestar los que los militares definieron como la "campaña antiargentina" 30 . Las presas políticas en muchas de las cartas que le escribían a sus familiares, les insistían en que el fanatismo por este evento deportivo, no les debía hacer olvidar la existencia de numerosos desaparecidos, un significante que para ese momento empezaba a contar ya con cierta relevancia, por lo menos entre los que se vieron afectados de manera directa por la represión. Algunas de las presas políticas, en concordancia con la prédica que los exiliados tenían sobre el Mundial de fútbol en Europa, por ejemplo, señalaron que era necesario utilizar este acontecimiento como una plataforma de denuncia para contar lo que estaba sucediendo en el país. Si sectores de la prensa extranjera les daban espacio en sus diarios a las Madres de Plaza de Mayo para publicar las listas de detenidos desaparecidos, las presas políticas apuntaban a que sus familiares se contactasen con estos periodistas para darles a conocer la falta de derechos con la que ellas vivían en la cárcel de Villa Devoto. A pesar de esta incesante actividad de denuncia, las presas políticas no pudieron evitar ni que desapareciesen a un puñado de presas políticas al obtener su libertad ni que el servicio penitenciario dejara sin atención médica a las de compañeras que tenían afecciones crónicas muy graves.

Los distintos actos de resistencia hasta aquí señalados ponen de manifiesto una agencia política compleja de estas mujeres por medio de la cual incluso lograron articular una red de alianzas con sus familiares, funcionarios/as de organismos de derechos humanos internacionales, abogados defensores de presos políticos y exiliados.

\section{La escritura como resistencia}

\footnotetext{
${ }^{30}$ Los militares llamaron "campaña antiargentina" a las denuncias que desarrollaron desde mediados de 1976 los exiliados en Europa, Estados Unidos y América Latina sobre las violaciones a los derechos humanos que se llevaban a cabo en el país.
} 
Outros Tempos, vol. 10, n.16, 2013 p. 171-193. ISSN:1808-8031

Otro espacio muy importante donde se enunció una indoblegable y encubierta resistencia fue en las cartas que las presas escribieron desde el penal de Villa Devoto a sus familiares. Estas cartas resultan una práctica discursiva específica que permite visibilizar cómo por años estas mujeres fraguaron distintos tipos de simulaciones escribiendo solo aquello que estaba permitido y expresando lo prohibido en forma de claves, guiños y marcas de orden íntimo. Estos escritos muestran la negociación de sentidos que cada una de ellas debió revelar entre las palabras y los silencios y en donde se cristalizó "el saber de la prisión y la posibilidad de dar movimiento a la quietud del tiempo". 31

De este modo entre el deseo y las transacciones con lo posible, censura mediante, prorrumpió la escritura femenina a modo de eludir el aislamiento y el control institucional. En el libro Nosotras presas políticas, una obra colectiva en la que participaron 112 mujeres, se explica que una carta para una presa política lo era todo: la vida misma y la conexión con el afuera. Una especie de puente semántico entre el mundo exterior y el mundo íntimo. Las presas se comunicaban con los familiares por medio de claves previamente trazadas y cuidadosamente socializadas. Así podemos ver cómo una de ellas se las arregló para escribir sobre el impacto emocional que le produjeron las muertes de Mario Roberto Santucho y de Benito Urteaga, dos importante dirigentes del PRT-ERP. Mezclando en el lenguaje lo personal y lo político de manera deliberada, Viviana, logró escribir sobre un colosal hecho político, una acción que estaba absolutamente prohibida por el régimen carcelario de esta etapa: "Madre querida este año maldito que terminó nos llenó de dolor, fue tremendo, al viejo y a mí nos golpeó con rudeza un accidente en julio que murieron 2 amigos que vivían con nosotros y fueron nuestros hijos". ${ }^{32}$ Muchos escritos cifraban códigos para desarrollar un modo de comunicación encubierto. Por ello Silvia escribe: "El tío Juan no ha movido un dedo por mí (...) nunca le ha interesado darme una ayuda, vos me decís que ahora él anda mejor, yo no lo creo, si algo se consigue de él, es porque toda la familia está dispuesta a cantarle las cuarenta...”33 El “tío Juan”, en el lenguaje que Silvia estableció con sus familiares, remitía puntualmente a las autoridades del

\footnotetext{
${ }^{31}$ INI, María Gabriela. "El tiempo quieto. Instancias de negociación y resistencia desde el encierro. Monjas y presas en el Asilo Correccional de Mujeres de Buenos Aires. 1939-1941", en: NARI, Marcela y FABRE, Andrea (Comp.). Voces de mujeres encarceladas. Buenos Aires. Catálogos, 2000, p. 183.

${ }^{32}$ El 19 de julio de 1976 fueron sorprendidos por las fuerzas de seguridad en un departamento de la zona de Villa Martelli, en el conurbano bonaerense, Mario Roberto Santucho y Benito Urteaga, y tras un breve tiroteo resultaron muertos. Ver la carta en BEGUÁN, Viviana et al. Nosotras, presas políticas, Op. Cit, p. 233.

${ }^{33}$ Carta de Silvia a sus familiares, Villa Devoto, 1978. Ver el CD ROM editado en Begúan et al. (2006).
} 
gobierno militar que le negaban sistemáticamente su libertad y la posibilidad de optar por el derecho de opción y salir del país.

Las cartas nos muestran además la precariedad material que rodeaba a estas mujeres en su cotidianeidad. Numerosas esquelas resultan interminables pedidos a los familiares de cosas nimias, como el arreglo del cierre de un pantalón, el envío de estampillas o de hojas para escribir más cartas, el pedido de un jabón para bañarse o fotos para decorar la celda. A la vez, las demandas materiales se entremezclaban con infinidad de pedidos y ruegos de afecto o también de quejas por la falta de atención. De este modo, la simple enunciación de una solicitud expresaba algo que iba más allá del simple pedido formal de algún artículo de primera necesidad faltante en el pabellón o en la celda.

Las cartas no operaban como meros vehículos de peticiones de efímeras demandas materiales. Las cartas se constituyeron en espacios de comunicación a la vez que en espacios de articulación de demandas incluso políticas, en las que las familias participaban, aunque esto a veces no haya sido especialmente grato para ellos.

Las cartas, en oportunidades, exhiben por parte de las mujeres presas decepciones y cansancio por lo que ellas entendían como una falta de compromiso e incomprensión de parte de sus familias. También los escritos ponen frecuentemente de manifiesto la insatisfacción por tener que siempre suplicarles por ciertas cosas. En varias oportunidades Silvia le escribió a su hermana pidiéndole noticias por su aislamiento, a la par que les exigía presencia en los días de visitas:

\footnotetext{
"con dos o tres noticias que me mandes, más las dos o tres de otras chicas, nos podemos más o menos dar una idea de lo que pasa en el mundo... basta con que una parte de la carta me comentes o transcribas algo del diario... hace bastante que no recibo carta tuya, ¿por qué es?... No puede ser que teniendo a mis parientes que me pueden escribir no lo hacen. Si vos supieras el valor que tiene aquí una carta. Esa necesidad te la tengo que hacer comprender yo, así que disculpá si te lo repito tantas y tantas veces". ${ }^{34}$
}

El modo de Silvia de luchar contra la desubjetivación fue religarse a sus familiares, tomar contacto con lo conocido, con lo íntimo. Numeroso escritos, sobre todo, durante los primeros años del encierro, revelan la necesidad de recomponer los vínculos rotos en tiempos pasados con las familias o con algún integrante de ella. A

\footnotetext{
${ }^{34}$ Carta de Silvia escrita en marzo de 1978 y dirigida a un familiar desde la cárcel de Devoto. Ver el CD ROM editado en BEGUÁN, Viviana et al. Nosotras, presas políticas, Op. Cit.

34 Ídem
} 
veces en las cartas las presas políticas se replantean la necesidad de un rencuentro con sus seres queridos para conocerlos mejor. Escribe Alicia a sus padres:

\begin{abstract}
"Un día cualquiera hablaremos mucho, y sabrán tantas cosas sucedidas en estos años para mí tan vivos y para ustedes tan confusos... en ambas hay impotencia, dolor, ausencias, presencias extrañas, tinieblas, decaimientos y algunos resplandores. Ergo, estamos cansados". 35
\end{abstract}

De este modo relaciones anteriormente quebradas se resignifican y se relanzan en la etapa de encierro. Incluso el rol de las madres pasa a ser fundamental en estas epístolas ya que ellas se constituyen en escuchas privilegiadas de sus hijas. ${ }^{36}$ Este aspecto refleja un modo de concebir el encierro como un espacio que capacita para discutir ciertas cosas, que tal vez de otro modo no hubiera sido posible trabar conversación. Ana le dice a sus padres, por ejemplo: "Estuve pensando mucho en ustedes y en mí, y en cómo después de toda una vida juntos, recién hace pocos años comenzamos a conocernos". ${ }^{37}$ También Mariana le habla a su padre con mucho amor y una profunda nostalgia:

\begin{abstract}
“porque mi papá, bueno es mi papá porque (...) y cuántas cosas puedo decir de él y cuántas cosas aprendí y (...) mi papá es un hombre sensible y fuerte. Y esas son dos cualidades esenciales porque van unidas a muchas más (...) no es teoría ni lindas palabras, sino que es la realidad dura de un país, de un mundo que busca sin tregua una paz, que será el fruto seguro de una lucha que aun con muchas lágrimas triunfará porque el amor determina la victoria”. ${ }^{38}$
\end{abstract}

Otras mujeres les reclaman a sus familias que no se resignen. Nora, por ejemplo, insiste con la idea de que "no aflojen", que "no se sientan abatidos". Incluso les reprocha cierta debilidad política y la incapacidad de ver el problema de la prisión

\footnotetext{
${ }^{35}$ Carta de Alicia escrita en febrero de 1978 y dirigida a sus padres desde la cárcel de Devoto. Ver el CD ROM editado en BEGUÁN, Viviana et al. Nosotras, presas políticas, Op. Cit.

${ }^{36}$ Es importante señalar que muchas familias no sabían a ciencia cierta el grado de compromiso de sus hijos e hijas con la militancia, algo que a medida que pasaban los años, de 1972 a 1976, era aún más acentuado. Este es el caso de Alicia Sanguinetti, quien estuvo presa en el penal de Rawson durante la dictadura de Alejandro Lanusse (1971-1973). En su testimonio ofrecido a la organización Memoria Abierta, que posee un importante acervo de testimonios orales de protagonistas de los año sesenta y setenta, Alicia señaló: "Mi familia se entera de la magnitud de la militancia, el día que yo caí presa". Entrevista a Alicia Sanguinetti, Buenos Aires, septiembre de 2002, Archivo Oral de Memoria Abierta.

${ }^{37}$ Carta de Ana escrita en julio de 1978 y dirigida a sus padres desde la cárcel de Devoto. Ver el CD ROM editado en BEGUÁN, Viviana et al. Nosotras, presas políticas, Op. Cit.

${ }^{38}$ Carta de Mariana escrita en 1976 y dirigida a su papá desde la cárcel de Devoto. Ver el CD ROM editado en BEGUÁN, Viviana et al. Nosotras, presas políticas, Op. Cit.
} 
política más allá del drama estrictamente personal por el que les toca pasar. Así les escribe:

\begin{abstract}
"No estoy amargada, entonces, vos tampoco te pongas mal. Con llorar y llorar a los compañeros, no se hace nada. Entonces ARRIBA (..) Nuestras actitudes tienen que servir de ejemplo. Por la carta que mamá me escribe, noto que el ánimo está por el suelo y eso me preocupa (....) También tratá de ver tu comportamiento en el colegio, no hagas cosas sin sentido, de puro rebeldes, porque ¿sabés? Siempre tenemos que demostrar y ser los mejores en todo. No podemos ser subjetivos, si no vemos solo una parte y no la totalidad". 39
\end{abstract}

En este sentido, también es muy provocativo el rol que cumplen algunas mujeres procurando administrar a distancia el ámbito doméstico que les fuera propio en otro momento. En las cartas se expresan muchas tensiones relacionadas con la crianza de los hijos ahora a cargo de sus familias de origen. Por ejemplo Ema le indica a su hija adolescente cómo debe cuidar a su hermanito bebé que acaba de ser retirado del pabellón de las "Madres" del penal de Villa Devoto. ${ }^{40}$

\begin{abstract}
"Le gusta dormir boca abajo para que le golpeen la espalda o la cola, pero igual se duerme jugando solo si lo dejás. Le gusta mucho leer revistas y escribirte a vos (...) el tiene una nana (ya que se quemó con agua hirviendo en la cárcel)." ${ }^{41}$.
\end{abstract}

También Ema a la vez le plantea a su propia hermana cómo debe atender a sus dos hijos. Si bien su hermana ha pasado por la experiencia de criar a tres niños propios y Ema confía en ella, lo cierto es que las recomendaciones, sugerencias y observaciones que le procura por carta, se relacionan más con un temor a que sus propios hijos la olviden a ella que con la crianza en sí. ${ }^{42}$

Las cartas exhiben la necesidad profunda que la mayoría de estas mujeres tuvieron de intervenir en sus hogares y de seguir paso a paso las vicisitudes de la vida de sus seres queridos. En estas esquelas, las presas hablan, piensan y discuten todo lo que sucede en las vidas de los integrantes de sus familias en libertad: los casamientos,

\footnotetext{
${ }^{39}$ Carta de Nora escrita en mayo de 1975 y dirigida a su hermana desde la cárcel de Olmos. Ver el CD ROM editado en BEGUÁN, Viviana et al. Nosotras, presas políticas, Op. Cit.

${ }^{40}$ Durante este período el servicio penitenciario permitía a las madres quedarse con sus hijos en sus celdas solamente hasta los seis meses de edad del niño o la niña. Por este motivo muchos de esos niños se criaron con sus familias maternas o paternas y algunos que no hallaron familiares que los acogieran terminaron boyando en los servicios de asistencia a la infancia como es el caso de la Casa Cuna.

${ }^{41}$ Carta de Ema escrita en el año 1977 y dirigida a su hermana desde la cárcel de Devoto. Ver el CD ROM editado en BEGUÁN, Viviana et al. Nosotras, presas políticas, Op. Cit.

42 Ídem.
} 
Outros Tempos, vol. 10, n.16, 2013 p. 171-193. ISSN:1808-8031

los viajes, el crecimiento de los niños, las decisiones para las fiestas de fin de año, los cumpleaños, los conflictos familiares, las graduaciones escolares, etc. No siempre, sin embargo, fueron espectadoras de estas múltiples situaciones vitales. Graciela, por ejemplo, le cuenta a la sobrina que se ha enamorado de un hombre que no es un hombre bello por fuera "sino hermoso por dentro". Que ella ha "caído" presa por él y que no está triste: "Tristeza no porque soy feliz de ser la compañera de este hombre (...) vergüenza tampoco porque no he hecho nada reprochable. Simplemente estuve al lado de un hombre que quiere la justicia". ${ }^{43}$

En ocasiones, las cartas que iniciaban como un acto privado de escritura y de comunicación entre una presa y un familiar, compañero o pareja, se terminaban convirtiendo en un acto comunicativo comunitario. Las presas políticas compartían las confidencias con las compañeras que no recibían correspondencia con el fin de animarlas y que no se desanimasen. A la vez estas mujeres socializaban las pocas noticias que llegaban del exterior. ${ }^{44}$ Las cartas entraban a la cárcel, entonces, a propagar novedades como antaño sucedía con aquellas epístolas que arribaban a los pueblos lejanos funcionando como el único medio de transmisión de novedades.

Las cartas que ingresaban a pesar de estar censuradas y seleccionadas por el poder penitenciario fueron, por períodos, sobre todo durante los dos primeros años del régimen militar, cuando estaban restringidas las visitas y la censura estuvo en su punto más alto, un medio importantísimo de información de lo que pasaba en el exterior. Las noticias que ellas portaban eran leídas en voz alta, "haciendo del acto privado un acto comunitario, que permite la transmisión de la información a un público más amplio". ${ }^{4}$ Estos escritos enlazaron, por tanto, a través de la lectura colectiva cientos de historias

\footnotetext{
${ }^{43}$ Carta de Graciela escrita en el año 1975 y dirigida a su sobrina desde la cárcel de Olmos. Ver el CD ROM editado en BEGUÁN, Viviana et al. Nosotras, presas políticas, Op. Cit.

${ }^{44}$ Esto sucedía, en buena medida, porque muchos familiares eran oriundos del interior del país y formaban parte de sectores populares que no habían tenido la posibilidad de alfabetizarse resultándoles gravosa la comunicación epistolar. En ocasiones, la falta de correo se debía también a una distancia prexistente en los lazos afectivos, los cuales se habrían deteriorado por las decisiones políticas tomadas por las propias mujeres militantes. Esto era tanto una represalia por haber elegido una vida política, cuanto por haber desarrollado una vida clandestina con identidad falsa, todos motivos por lo que las familias no tuvieron información ni siquiera cuando estas mujeres fueron recluidas en las cárceles. Este es el caso de Berta, una militante del PRT-ERP, a quien hemos tenido el gusto de entrevistar. Otras familias también estuvieron temerosas de las consecuencias políticas y por momentos se alejaron de sus seres queridos encarcelados.

${ }^{45}$ Castillo trata el tema del estatuto epistemológico de las epístolas. Ver CASTILLO, Darcie Doll. "La carta privada como práctica discursiva. Algunos rasgos característicos", en Revista Signos, volumen 35, N. ${ }^{\circ}$ 51-52, 2002, Valparaíso, p. 36.
} 
Outros Tempos, vol. 10, n.16, 2013 p. 171-193. ISSN:1808-8031

individuales y la escritura íntima estimuló la sociabilidad con otras mujeres. ${ }^{46}$ A la vez todas estas cartas funcionaron como un motor de difusión ideológica porque les permitía a estas mujeres discutir una serie de elementos políticos de la realidad externa.

\section{Algunas conclusiones}

En este texto he repasado las formas que encontraron las presas políticas del penal de Villa Devoto, a pesar de las múltiples limitaciones ejercidas por el tratamiento penitenciario, para construir espacios de autonomía y de solidaridad entre ellas. La performance reiterada y abierta de resistencia frente al poder penitenciario se sostuvo en las condiciones especiales que tenía la cárcel metropolitana de Villa Devoto. Esta fue una ventaja de género que las presas políticas supieron utilizar ciertamente a su favor. Las resistencias fueron algunas más solapadas que otras y se dimensionaron según los momentos internos de cada pabellón y en razón de la coyuntura política local del país.

Carentes de opciones revolucionarias realistas las presas lucharon con la idea de politizar todo reclamo aunque este fuese por condiciones mínimas de sobrevivencia. Desde esta posición intentaron hacer cumplir los elementos más benévolos del "reglamento" con el propósito de no someterse a las arbitrariedades y discrecionalidades penitenciarias. Se propusieron discutir con los carceleros y carceleras razones políticas con el fin de erosionar su actitud de victoria frente a ellas. Optaron por ofrecerles diagnósticos y herramientas políticas a los familiares a través de sus cartas. A la vez cuando les fue posible confeccionaron complejos escritos judiciales en su propia defensa para ser enviados a los magistrados.

El alto nivel de politización en los vínculos les permitió mantener fuertes lazos solidarios así como minimizar las formas de humillación que ejercía el poder penitenciario sobre ellas. Tal como señala Ana Guglielmucci, "las distintas prácticas recreadas por las prisioneras políticas generaron ámbitos de integración que tendieron a

\footnotetext{
${ }^{46}$ No contamos con investigaciones que comparen la experiencia de la escritura entre presas políticas y presas comunes durante los años setenta. Pero sin embargo sí conocemos la importancia de la escritura para el proceso de resubjetivación a través de la experiencia del proyecto "Yo no fui". Este es un proyecto de un grupo de reciente formación en la cárcel de Ezeiza (provincia de Buenos Aires), que le propone a las mujeres encerradas y a aquellas que tienen libertad condicional y salidas transitorias, reconstituir su subjetividad a partir del ejercicio de escritura. Tal como declara "Yo no fui", el objetivo es acompañar un proceso de recuperación de la libertad brindando un marco de contención emocional y promoviendo una comunicación libre de discriminación y segregación. Consultar en http://proyectoyonofui.blogspot.com
} 
Outros Tempos, vol. 10, n.16, 2013 p. 171-193. ISSN:1808-8031

neutralizar los dispositivos de segregación del penal". ${ }^{47}$ En este sentido y desde nuestro punto de vista, estas prácticas horizontales se convirtieron en hegemónicas a la hora de moderar las diferencias políticas y los roces de la convivencia que efectivamente existieron entre ellas en la cotidianeidad carcelaria. Esa etapa se prolongó a su manera, en la socialización posterior que muchas de estas mujeres ensayaron luego de que fueron liberadas.

\section{BIBLIOGRAFÍA}

ACTIS, Munú; et al. Ese Infierno. Conversaciones de cinco mujeres sobrevivientes de la ESMA. Buenos Aires, Editorial Sudamericana. 2001.

ANTOGNAZZI, Irma. "La vida en las cárceles de mujeres durante la dictadura argentina”, en Antognazzi, Irma y Ferrer, Rosa. Del Rosariazo a la democracia del 83. Rosario, Universidad Nacional de Rosario. 1988.

BEGUÁN, et al. Nosotras, presas políticas (1974-1983). Buenos Aires, Nuestra América.. 2006.

CASTILLO, Darcie Doll. “La carta privada como práctica discursiva. Algunos rasgos característicos”, en Revista Signos, volumen 35, n. ${ }^{\circ}$ 51-52, Valparaíso, pp. 33-57. Se puede consultar su versión online en http://www.scielo.cl33-57. 2002.

CLARA, Mirta. “La situación de la mujer en la cárcel, 1976-1983”, en http://www.pparg.org/pparg/carceles/globalidad/analisis. 1989.

GARAÑO, Santiago. Entre resistentes e "irrecuperables": Memorias de ex presas y presos políticos (1974-1983). Tesis de Licenciatura, FFyL, UBA. 2008.

GILMAN, Claudia. Entre la pluma y el fusil. Debates y dilemas del escritor revolucionario en América Latina. Buenos Aires, Siglo XXI. 2003.

GUGLIELMUCCI, Ana. "Vida cotidiana en la cárcel de Villa Devoto", en Lucha Armada en la Argentina, n. ${ }^{\circ}$ 7. 2006.

INI, María Gabriela. "El tiempo quieto. Instancias de negociación y resistencia desde el encierro. Monjas y presas en el Asilo Correccional de Mujeres de Buenos Aires. 1939-1941", en: Nari, Marcela y Fabre, Andrea (comp.). Voces de mujeres encarceladas. Buenos Aires, Catálogos. 2000.

SCOTT, James. Los Dominados y el Arte de la Resistencia, México, ERA. 2000.

TAYLOR, Diane. Dissapearing acts. Spectacles of Gender and Nationalism in Argentina's “Dirty War". Duke University Press, Durham and London. 1997.

\footnotetext{
${ }^{47}$ GUGLIELMUCCI, Ana. "Vida cotidiana en la cárcel de Villa Devoto", Op. Cit, p. 49.
} 